\title{
Research of the chemical composition peculiarities of food additives - vegetable lecithins for the development of methods for assessing their quality
}

\author{
Ekaterina Lisovaya*, Elena Viktorova, Mariet Zhane, Olga Vorobyova, and Elena \\ Velikanova
}

Krasnodar Research Institute of Storage and Processing of Agricultural Products - branch of the Federal State Budgetary Scientific Institution «North Caucasian Federal Research Center for Horticulture, Viticulture, Winemaking», Topolinaya alleya str., 2, Krasnodar, 350072, Russia

\begin{abstract}
Lecithins are widely used in the food industry as food additives. In this regard, the requirements for the lecithins quality are quite high, and the development of the rapid determination methods of their quality indicators, including the acid value, is an urgent task. The article presents research of the peculiarities of vegetable lecithins chemical composition for the development of a method for determining their acid value using the pulsed nuclear magnetic relaxation (NMR) method. It was found that the studied lecithins differ significantly in the content of individual phospholipid groups exhibiting acidic properties. As a result of the research of the fatty acid composition of the lecithins acetone-soluble fractions, it was found that the highest total content of monounsaturated fatty acids is a characteristic of sunflower oleic type lecithins $(81.3 \%)$ and rapeseed lecithins $(66.3 \%)$, and polyunsaturated fatty acids - sunflower linoleic type lecithins $(63.6 \%)$ and soybean lecithins $(67.7 \%)$. Researches of the NMR characteristics of lecithins with the introduction of carbon tetrachloride $\left(\mathrm{CCl}_{4}\right)$ have been carried out. It was found that the redistribution of component composition in the "lecithin- $\mathrm{CCl}_{4}$ " system occurs at different ratios for each type of lecithin, which is due to their chemical composition peculiarities.
\end{abstract}

\section{Introduction}

Vegetable lecithins are by-products obtained from the oilseeds processing [1]. Vegetable lecithins are a multicomponent system consisting mainly of phospholipids, triacylglycerols (TAG), and a small amount of other oilseeds cell membranes structural components (free fatty acids, glycolipids, etc.) $[2,3]$. Phospholipids and other polar lipids are insoluble in acetone and contained in the acetone-insoluble fraction of lecithins, while the molecules of TAG and free fatty acids (FFA) are contained in the acetone-soluble fraction [4].

\footnotetext{
"Corresponding author: e.kabalina@mail.ru
} 
Lecithins are widely used in food technology as food additives due to their unique properties [5-8].

The main raw material for the production of lecithins in the world is soybean. This is related, firstly, to the large areas of soybean cultivation and the volume of soybean oil production, and, secondly, to the high content of phospholipids in soybean oil (up to $3.0 \%$ ) compared to other vegetable oils [9-11]. In industrial volumes, lecithins are also produced from sunflower and rapeseed oils [12, 13].

In Russia, the main oilseed crop is sunflower. It should be noted that Russia and Ukraine are the main world producers of sunflower seeds and oil from it, and, consequently, lecithins. Usually raw material for the sunflower lecithin production is oil obtained during the processing of sunflower seeds of modern selection with linoleic acid predominance up to $77.0 \%$.

However, at present, in Russia, the sown area of high oleic sunflower varieties and hybrids and the oil production volume from it with oleic acid predominance has increased to $92.0 \%$, at the same time, the production volumes of sunflower oleic type lecithin are insignificant.

The main lecithins quality indicators, which are regulated by both Russian standards and foreign regulations, are: the content of acetone-insoluble (AI) matter, that is, polar lipids; moisture and volatile matter; the content of toluene insoluble matter; acid value (AV) and peroxide value $[4,14]$.

It should be noted that the standard methods for determining some of the listed parameters are prolonged and require the use of a sufficiently large chemical reagents amount, and laboratory assistant qualification affects the measurement results accuracy.

Thus, the instrumental methods development for the operational and automated determination of lecithin quality indicators is an urgent task.

One of the promising methods, on the basis of which it is possible to determine the lipidcontaining products quality indicators, including lecithin, is the pulsed nuclear magnetic relaxation (NMR) method [15].

The aim of the research was to investigate the features of the food additives chemical composition - plant lecithins to develop a method for determining their acid number using the pulsed NMR method.

\section{Materials and methods}

The objects of the study were samples of liquid vegetable lecithins produced at Russian oil and fat factories: soybean, rapeseed, sunflower linoleic and sunflower oleic types. Ten samples of liquid lecithins of each type with AI $62.5 \%$ were taken for the study.

The studied samples of lecithin were selected in such a way that their physicochemical indicators were as close as possible. Physicochemical indicators were analyzed according to the Russian standard.

To determine the content of FFA in the acetone-soluble fraction of lecithins, they were saponified with a sodium hydroxide solution. The obtained soaps were decomposed with a solution of sulfuric acid with the release of fatty acids, which were quantitatively extracted with a solvent, the solvent was distilled off under vacuum, and the isolated fatty acids were dried to constant weight.

The fatty acid composition of the acetone-soluble and acetone-insoluble fractions of lecithin was determined using the gas-liquid chromatography method on a chromatograph "Chromatek-Crystal 5000" (ZAO SKB "Chromatek", Russia).

The composition and content of individual phospholipids of lecithins was investigated using the thin layer chromatography (TLC) method with densitometric plates identification. For TLC method, plates with a layer of silica gel on an aluminum substrate of Sorbfil brand 
and a solvent system of chloroform, methanol and water in the volume proportion $65: 25: 4$ were used. In addition, the identification of individual phospholipids was carried out using high performance liquid chromatography on an Agilent 1260 Infinity chromatograph (Agilent Technology, United States).

The nuclear magnetic relaxation characteristics lecithin samples were studied on an upgraded AMV-1006M NMR analyzer (VNIIMK, Russia), which is based on the proton magnetic resonance method.

The research was carried out using the equipment of the Research Center for Food and Chemical Technologies of KubSTU (ckp_3111).

\section{Results and discussion}

The AV of lecithins depends on the content of lipids, exhibiting acidic properties, which include FFA and some phospholipids, such as phosphatidylserine (PS) and phosphatidic acid (PA).

It was found that in the studied lecithin samples the FFA content is in the range of 4.5 $4.8 \%$ and does not depend on the vegetable lecithin type.

The content of phospholipids, exhibiting acidic properties in the studied lecithin samples are shown in Fig. 1.

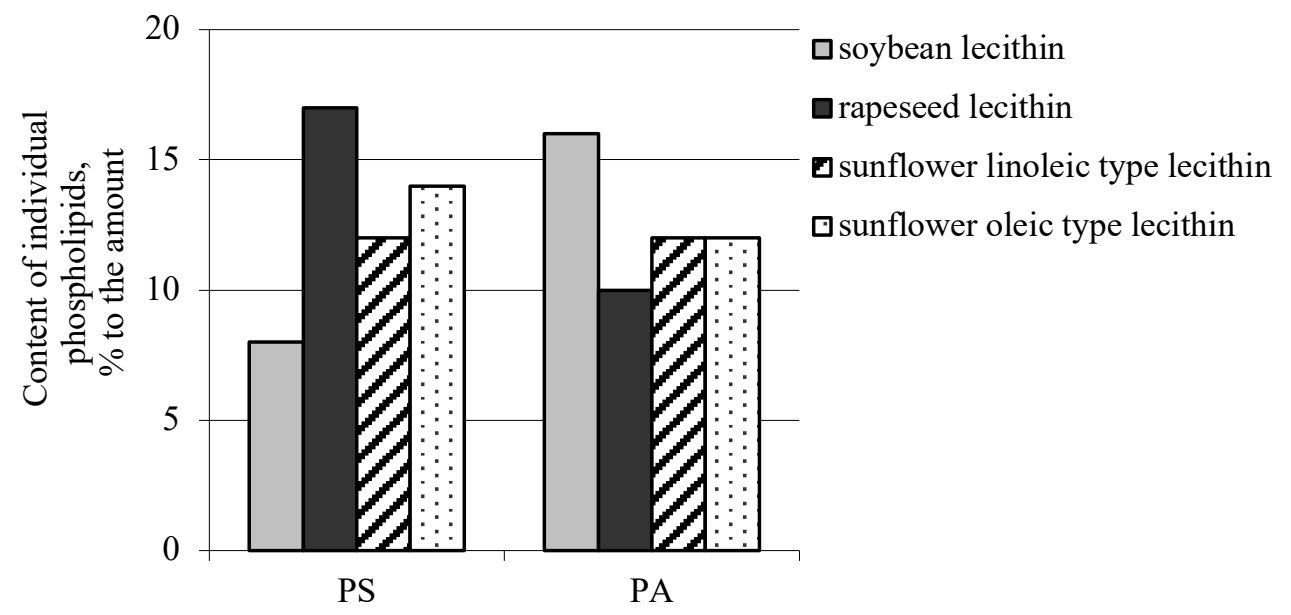

Fig.1. The content of individual phospholipids exhibiting acidic properties in lecithins

The content of PS is highest for rapeseed lecithins compared to another studied lecithins samples. The highest content of PA has soybean lecithin in comparison with sunflower lecithins of linoleic and oleic types, as well as with rapeseed ones.

It should be noted that in terms of the content of phospholipids, exhibiting acidic properties, sunflower linoleic type lecithin practically does not differ from sunflower oleic type lecithin.

At the next stage, the fatty acids composition of acetone-soluble and acetone-insoluble fractions of lecithins was investigated, since the degree of saturation of fatty acids affects the structure and association of FFA, TAG and phospholipid molecules in lecithin.

Fig. 2 shows the data characterizing the total content of saturated (SFA), monounsaturated (MUFA) and polyunsaturated (PUFA) fatty acids in the acetone-soluble and acetoneinsoluble fractions of lecithins.

From the data presented in Fig. 2 (A), it can be seen that the total content of SFA, MUFA, 
and PUFA in the acetone-soluble fractions of the vegetable lecithin samples significantly differ.

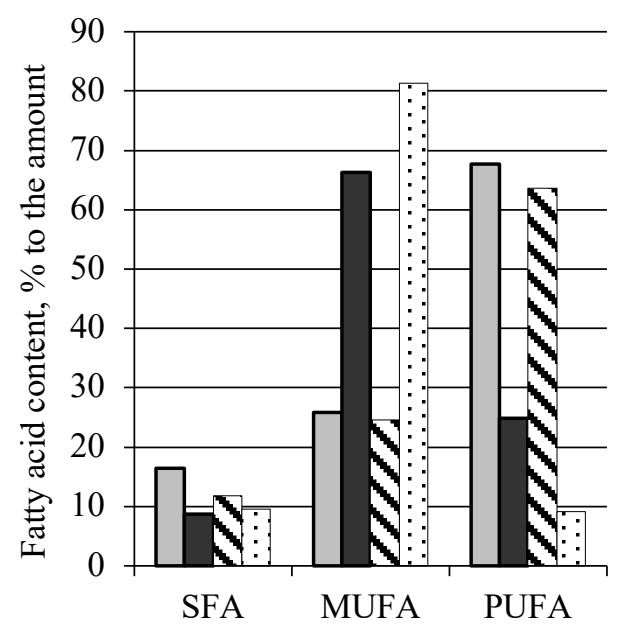

A)

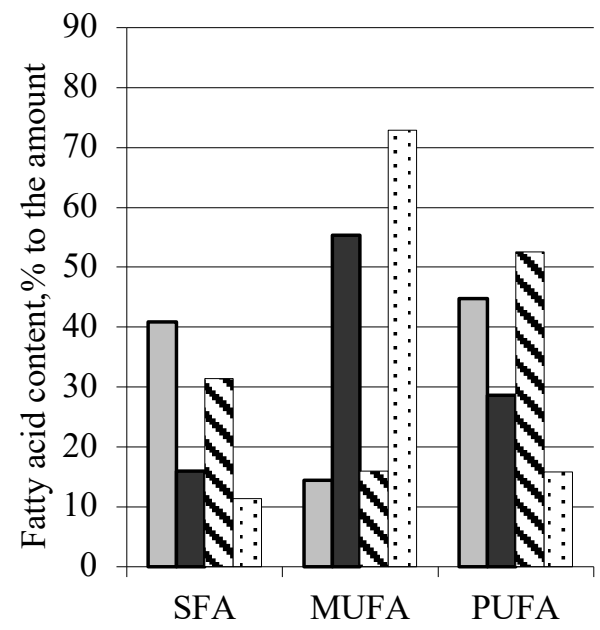

B)

Fig.2. Fatty acid composition of acetone-soluble (A) and acetone-insoluble (B) fractions of: soybean lecithin $(\square)$;rapeseed lecithin ( $\square$ ); sunflower linoleic type lecithin ( $\square$ ); sunflower oleic type lecithin $(\square)$

The highest concentration of MUFA has acetone-soluble fractions of sunflower oleic type lecithins $(81.3 \%)$ and rapseed lecithins $(66.3 \%)$. The highest concentration of PUFA has acetone-soluble fractions of sunflower linoleic type lecithins $(63.6 \%)$ and soybeans lecithins $(67.7 \%)$.

Considering that SFA and MUFA are most prone to the formation of associates-dimers, compared with PUFA, the molecules of FFA and TAG in the acetone-soluble fractions of sunflower lecithins oleic type and rapeseed lecithins are more prone to association as compared to soybean lecithins and sunflower lecithins linoleic type.

Fatty acid composition of acetone-insoluble fraction of lecithins changes similarly (Fig.2 (B)). However, the fatty acid composition of the acetone-insoluble lecithins fraction is more saturated than that of the acetone-soluble lecithins fraction.

In [16], we showed that to develop a method for determining the AV of lecithins using the pulsed NMR method, it is necessary to convert lipids exhibiting acidic properties (FFA, PS and PA) into sodium soaps using sodium hydroxide.

However, vegetable lecithins are complex systems, while TAG, FFA and phospholipids in lecithins are in the form of individual molecules, as well as associates-dimers and micelles of various orders.

Taking this into account, it is necessary to reduce the degree of micelle formation of phospholipids and association of FFA by adding a non-polar solvent to lecithin, which will increase the individual molecules content in the system.

In $[17,18]$, data are given characterizing the process of micelle formation of phospholipids of vegetable lecithins in a non-polar solvent - carbon tetrachloride $\left(\mathrm{CCl}_{4}\right)$.

We found that vegetable lecithins, according to their ability to micelle formation in $\mathrm{CCl}_{4}$, can be arranged in a row (in ascending order): soybean, rapeseed, sunflower linoleic type, sunflower oleic type.

At the next stage, we investigated the nuclear magnetic relaxation characteristics of lecithins and the change in these characteristics upon the introduction of $\mathrm{CCl}_{4}$ in a certain 
weight ratio.

It should be noted that the amplitude of the NMR signals allows one to quantify the content of individual components in the system.

Fig. 3 shows a comparative assessment of the content of protons of components in lecithin (control) and in the "lecithin - $\mathrm{CCl}_{4}$ " system for the studied lecithin samples.

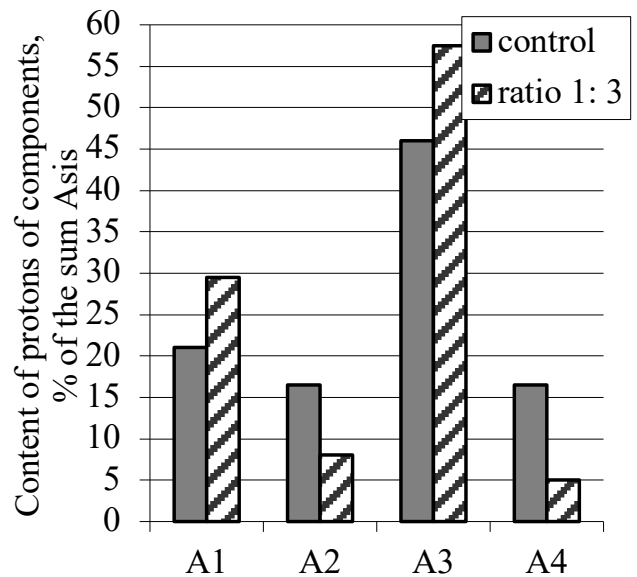

A)

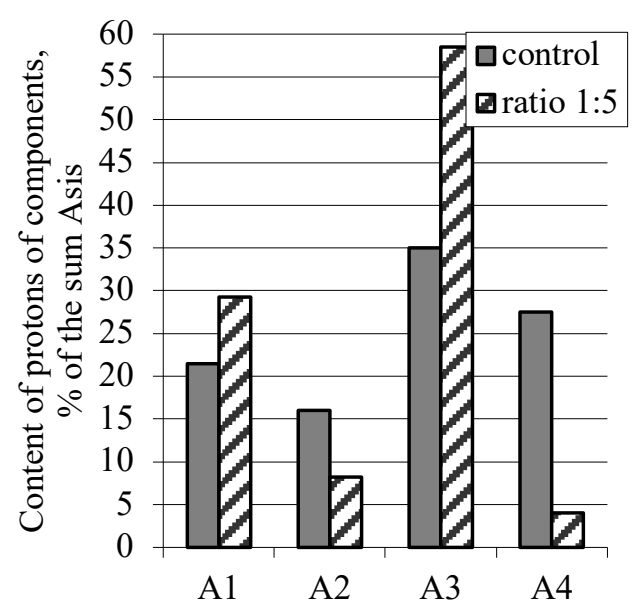

C)

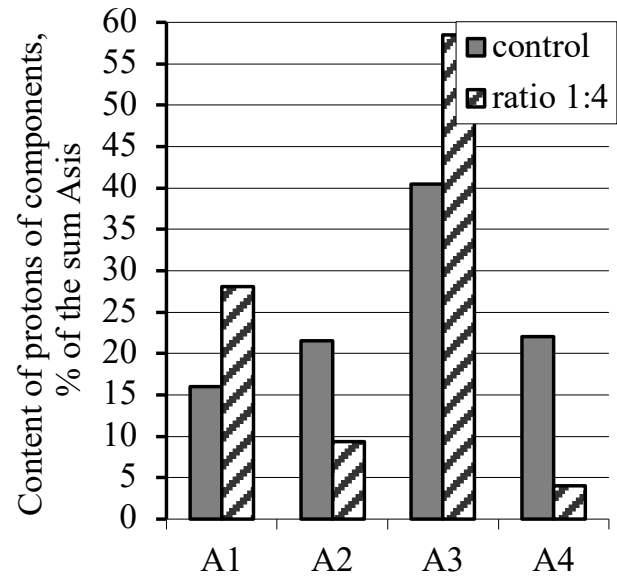

B)

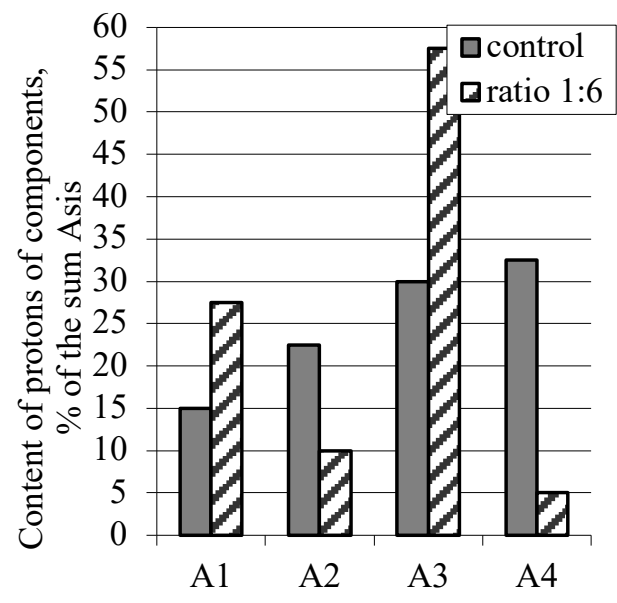

D)

Fig.3. Comparative assessment of the content of protons of components in lecithin (control) and in the system "lecithin $-\mathrm{CCl}_{4}$ " for: A) soybean lecithin; B) rapeseed lecithin; C) sunflower linoleic type lecithin; D) sunflower oleic type lecithin

It has been found that when $\mathrm{CCl}_{4}$ is added to lecithins, regardless of lecithin type, redistribution of the individual components content occurs in the "lecithin-CCl4" system.

The first component (A1), which characterizes the content of TAG and FFA individual molecules in the system, increases due to the release of these molecules from associatedimers. The second component (A2), which characterizes the content of TAG and FFA associates-dimers in the system, decreases. The third component (A3), which characterizes the content of phospholipids in the low-order micelles form in the system, increases, and the fourth component (A4), which characterizes the content of phospholipids in the high-order 
micelles form in the system, decreases.

Such a redistribution of individual components is achieved with a different ratio of lecithin and $\mathrm{CCl}_{4}$ in the system and depends on the lecithin type. This is due to the peculiarities of the studied vegetable lecithins chemical composition, and, consequently, to the difference in the ability of the molecules of TAG, FFA, and phospholipids contained in lecithins to associate and micelle formation.

\section{Conclusions}

Based on the research, it can be concluded that in order to develop the method for determining the acid value of food additives - vegetable lecithins using the pulsed NMR method, it is necessary to carry out a special sample preparation for each vegetable lecithin type, which is due to the their chemical composition peculiarities. In this case, the procedure for measuring the acid value can be the same for all vegetable lecithins types.

\section{References}

1. W. van Nieuwenhuyzen, In: M.U. Ahmad, X. Xu (eds.) Polar Lipids, 245-276 (Academic Press, AOCS Press, 2015) https://doi.org/10.1016/B978-1-63067-044-3.50013-3

2. J.Li, X.Wang, T. Zhang, C. Wang, Z. Huang, X. Luo, Y. Deng, Asian J. Pharm. Sci., 10(2), 81-98 (2015) https://doi.org/10.1016/j.ajps.2014.09.004

3. C. Robert, L. Couëdelo, C. Vaysse, M.C. Michalski, Biochimie, 169, 121-132 (2020) https://doi.org/10.1016/j.biochi.2019.11.017

4. M.T. Nguyen, D. Van de Walle, C. Petit, B. Beheydt, F. Depypere, K. Dewettinck, J. Am. Oil Chem. Soc., 91, 1093-1101 (2014) https://doi.org/10.1007/s11746-014-2455-9

5. E.A. Butina, E.O. Gerasimenko, I.A. Bugaets, I.A. Dubrovskaia, J. Pharm. Sci.\& Res., 9(12), 2493-2497 (2017)

6. S Delacharlerie, R Petrut, S Deckers, E Flöter, C. Blecker, S. Danthine, LWT - Food Sci. Technol., 72, 552-558 (2016) https://doi.org/10.1016/j.lwt.2016.04.043

7. I.Lončarević, B. Pajin, J. Petrović, D. Zarić, M. Sakač, A. Torbica, D.M. Lloyd, R. $\begin{array}{lllll}\text { Omorjan, J. Food } & \text { Eng., } & \text { 171, } & \text { 67-77 }\end{array}$ https://doi.org/10.1016/j.jfoodeng.2015.10.001

8. F. Bot, D. Cossuta, J.A. O'Mahony, Trends Food Sci. Technol., 111, 261-270 (2021) https://doi.org/10.1016/j.tifs.2021.02.028

9. M.J. Alhajj, N. Montero, C.J. Yarce, C.H. Salamanca, Cosmetics, 7(4), 87 (2020) https://doi.org/10.3390/cosmetics7040087

10. G.R. List, In: M.U. Ahmad, X. Xu (eds.) Polar Lipids, 1-33 (Academic Press, AOCS Press, 2015) https://doi.org/10.1016/B978-1-63067-044-3.50005-4

11. D.K. Agarwal, S.D. Billore, A.N. Sharma, B.U. Dupare, S.K. Srivastava, Agric Res, 2, 293-300 (2013) https://doi.org/10.1007/s40003-013-0088-0

12. D. Lehri, N. Kumari, R.P. Singh, V. Sharma, Plant Sci. Today, 6(sp1), 613-622 (2019) https://doi.org/10.14719/pst.2019.6.sp1.682

13. W. Van Nieuwenhuyzen, Int. News Fats Oils Relat. Mat., 25(4), 254-259 (2014).

14. A. Mortensen, F. Aguilar, R. Crebelli, A. Di Domenico, M.J. Frutos, P. Galtier, D. Gott, U. Gundert-Remy, C. Lambré, J.C. Leblanc, O. Lindtner, P. Moldeus, P. Mosesso, A. Oskarsson, D. Parent-Massin, I. Stankovic, I. Waalkens-Berendsen, R.A. Woutersen, M. Wright, M. Younes, L. Brimer, A. Altieri, A. Christodoulidou, F. Lodi, B. Dusemund, EFSA J., 15 (4), 4742 (2017) https://doi.org/10.2903/j.efsa.2017.4742

15. O. Agafonov, S. Prudnikov, E3S Web Conf., 176, 03012 (2020) http://doi.org/10.1051/e3sconf/202017603012 
16. E.V. Lisovaya, M.R. Zhane, O.S. Agafonov, E.P. Viktorova, Novye Tehnologii (Majkop), 3(53), 38-47 (2020)

17. E.P. Viktorova, E.V. Lisovaya, M.R. Zhane, V.I. Martovshchuk, L.A. Marchenko, O.S. Vorontsova, News of institutes of higher education Food technology, 1 (373), 91-93 (2020) http://doi.org/10.26297/0579-3009.2020.1.25

18. E.V. Lisovaya, M.R. Zhane, S.G. Efimenko, V.I. Martovshchuk, E.P. Viktorova, News of institutes of higher education Food technology, 1(378), 12-15 (2021) http://doi.org/10.26297/0579-3009.2021.1.2 